Revista de la red interuniversitaria de estudios sobre las literaturas rioplatenses contemporáneas en Francia

$11 \mid 2014$

De niños e infancias

\title{
Fragmento de Acá todavía (inédita)
}

\section{Romina Paula}

\section{OpenEdition}

Journals

\section{Edición electrónica}

URL: http://journals.openedition.org/lirico/1834

DOI: $10.4000 /$ lirico. 1834

ISSN: 2262-8339

Editor

Réseau interuniversitaire d'étude des littératures contemporaines du Río de la Plata

Referencia electrónica

Romina Paula, « Fragmento de Acá todavía (inédita) », Cuadernos LIRICO [En línea], 11 | 2014, Puesto en línea el 01 diciembre 2014, consultado el 01 mayo 2019. URL : http://journals.openedition.org/ lirico/1834 ; DOI : 10.4000/lirico.1834

Este documento fue generado automáticamente el 1 mayo 2019.

\section{(c) (i) (9)}

Cuadernos LIRICO está distribuido bajo una Licencia Creative Commons Atribución-NoComercialSinDerivar 4.0 Internacional. 


\title{
Fragmento de Acá todavía (inédita)
}

\author{
Romina Paula
}

\section{NOTA DEL EDITOR}

Romina Paula (Buenos Aires, 1979). Publicó las novelas ¿Vos me querés a mí ? (Entropía, 2005) y Agosto (Entropía, 2009). Como dramaturga y directora estrenó las obras Si te sigo, muero (basada en textos de Héctor Viel Temperley, 2005), Algo de ruido hace (2007), El tiempo todo entero (2009) y Fauna (2013). El siguiente texto es un fragmento de su próxima novela Acá todavía que se publicará en 2015.

1 Y en ese irme yendo, ese dormitando, ese sopor, me vuelve vaya uno a saber de dónde ni para qué, vuelve Dolores, el amor de verano, Dolores la escuálida en las playas uruguayas, Dolores y su familia católica y yo, desvelada por esa Dolores día tras día. Dolores que pasaba los días con su familia en la playa bajo la sombrilla justo junto a la nuestra. Dolores que tenía un hermano mayor y una hermana menor, Sebastián y Clara, la hermanita. Dolores que era preciosa : pelirroja de pecas, fibrosa y alta. Tenía ese pelo largo, naranja y un poco ondulado que yo observaba día tras día, la buscaba, quería acercarme a ella, ése era mi objetivo y no había razón para ocultarlo. Dolores y sus hermanos se metían al mar y yo iba detrás, sin disimulo. Me zambullía justo al lado de la familia de mi objeto de deseo, saltaba las mismas olas, los miraba cómplice, les festejaba las risas. La familia de Dolores salía del agua y yo salía detrás. Hasta que un mediodía agarré mi balde y me dispuse a recoger caracoles al ras de la arena. En mi mallita azul de flores blancas y bordes rojos gateaba en la arena y echaba las piezas preciadas dentro del balde, una por una, una por una, lamiendo la estela de conchilla y caracoles. En mi desplazarme reptando me acercaba irremediablemente a la porción de playa donde estaba la sombrilla de la chica roja. Y ella que no reacciona al pavoneo de seducción y es la madre la que tiene que indicarle que hay ahí alguien trabajando por ella. La madre le dice a Dolores que vaya a jugar con la nena. Andá a jugar con la nena, le dice, y Dolores va. $Y$ a partir de entonces Dolores se convierte en Dolores y yo en Andre, a partir de entonces todo ese veraneo hace mucho sentido. 
2 Descubrimos, entre otras cosas, que las dos vivimos en San Isidro (eso me da esperanzas de sobrevivir al amor de verano o de que pueda incluso convertirse en algo serio). Descubro también que mi amiguita amiga es dos años más joven, y que soy yo, a mis ocho, la que parece de seis. Con Juani, entonces, vamos a pasar la mayor parte de los días de playa en las dunas con Dolores y sus hermanos, Juani se va a hacer un poco amigo de Sebastián, aunque no mucho, y a Clarita, la hermanita mañosa, la vamos a tener siempre colgando. Descubro también, en ese verano y para mi gran sorpresa, cuánto poder puede tener la pertenencia a una iglesia, un credo, sobre la vida más cotidiana: lo descubro porque me lo cuenta ella misma y porque habla mucho de eso, porque Dolores cree mucho en dios, en el dios católico, el único, el de las iglesias con cruces en las puntas, el señor viejo y bueno de barba blanca. Dolores cree mucho en él y toda su familia también. Yo no quiero decepcionarla y le digo que yo también, que también yo creo en dios, en ese dios, el de barbas, y en Jesús también, tan bueno y joven y sufrido. Prefiero guardarme para mí la fascinación que me produce el dios bruto, déspota y vengativo del antiguo testamento, el de las pestes y los ríos llenos de sangre humana, el de los hermanos que matan a palos al menor y lo tiran a una zanja por envidia, el de los oráculos y las profecías y los carneros degollados, de los mares que se abren y las lecciones que se graban a fuego en piedra y se pagan con la peor de las muertes. No quiero ni decepcionar ni atemorizar a mi amiga y me hago la del Nuevo Testamento, la de la comunión y la hostia y el vestidito blanco, me hago la que sí, la que está bautizada y que va a tomar la comunión pronto, la que va a catequesis. Sé de la palabra catequesis por algunas chicas del colegio que van a catequesis los sábados antes de ir a misa. Pero la mayoría de las chicas y chicos del colegio son protestantes y entonces no toman la comunión sino que directamente se confirman. A los chicos del colegio, cuando me preguntan de qué religión soy, les digo que evangélica. Y cuando me preguntan si estoy bautizada les digo que todavía no pero que quiero y que cuando me confirme me voy a bautizar, todo al mismo tiempo, y que ya averigüé y que es algo que se hace y que no hay problema. Entonces a Dolores prefiero no decirle lo de mis planes de confirmarme en el protestantismo sino que me finjo católica de cepa y digo catequesis y padrenuestro y comunión.

3 Hasta que una tarde Dolores nos invita a su cumpleaños, a Juani y a mí; Dolores cumple en enero. Juani y yo nos empilchamos ese día, es una tarde que no vamos a la playa sino al dúplex que alquilaron los Báez. Estoy tan entusiasmada como nerviosa por ver a Dolores en su casa, vestida de nena de cumpleaños y no de malla. Esa tarde Mario nos lleva hasta el dúplex entre los árboles y promete pasar a buscarnos en un par de horas. Elegí para la ocasión el jean gastado pero limpio, una remerita de hilo en rosas y amarillos que me tejió la abuela y unas zapatillas rosa marca Allegro que son el hit del verano, aún sin ser de marca. Me siento decentemente linda aunque no estallada. Y sin embargo ya desde el desembarco del Renault, intuyo que no me va a gustar mucho Dolores fuera de la playa, y que mi jean curtido no habrá de causar en ella el efecto buscado : lo que proyecté como vida, horas de juego encima, puede ser aquí malentendido como... ¿negligencia, desidia, mal gusto ? La Dolores que cumple años va de vestidito ñoño, blanco, rosa o celeste, de cuello ancho y media cola, su hermoso pelo revuelto domesticado en una media cola muy tirante. Dolores está contenta de verme pero no en particular porque tiene a otras muchas amigas de vestido de cuello amplio alrededor. Las nenas son primas y amigas y todas se llaman María algo, María del Pilar, María José, María Luján, María solo. Mi hermano y yo somos los únicos de jean; yo -definitivamente- soy la única nena de jean. Esta Dolores vaporosa y engreída, pasada de femenina, en ese vestido subrayador, no me 
gusta mucho, incluso me da un poco de vergüenza. Y que encima, fea y todo, ose no prestarme demasiada atención, termina por desilusionarme. Me recuerdo quedando pegada a Juani toda la tarde, como imantada, recuerdo a la madre de Dolores queriendo integrarnos, recuerdo aceptar una porción de torta con crema y durazno en almíbar, comer sólo un poco y buscar la oportunidad de descartarla en algún lado sin levantar sospecha; me recuerdo en el pasto de adelante del chalet dúplex, en una pequeña ronda con mi hermano y Sebastián, el único fiel en esa familia de indiferentes, a salvo él mismo, probablemente, de tanto ruedo de vestido agitado.

4 Las horas son eternas hasta que vuelve Mario y estoy desesperada por sacarme el estúpido jean y la ridícula y anticuada remera tejida que ya nadie lleva. ¿Cómo explicarle a mi madre y a su mamá que ya nadie lleva cosas hechas con la mano y que las chicas cancheras se visten en boutiques como Juvenilia y no con ropa que hace la abuela imitando el modelo de Juvenilia? ¿Cómo hacer para hacerles entender eso sin romperles el corazón? ¿En qué momento me dejé convencer por alguien -la abuela, mi mamá- de que esa remerita al hilo era una buena idea y de que era una pieza especial porque estaba hecha a mano y nadie podía tener una igual? ¿Por qué extraña razón mi abuela y mi mamá creían que yo quería -de hecho- llevar una prenda única, destacarme, sobresalir ? ¿Por qué no me compraban esa prenda de la vidriera y basta? Mi madre hacía entonces siempre una cosa odiosa que era entrar al negocio, pedir la prenda, mirarla, medirla con los dedos, preguntar cuánto salía, agradecer, salir del negocio y decir que esa prenda no valía eso que decían, que por cuatro o cinco o veinte veces menos compraba la tela en un negocio de telas y la abuela cosía uno igual. o mejor incluso. Haber tenido la prenda tan cerca, tan a mano y tener que caer luego en el lento -lentísimo- proceso de la manufactura era para mí un auténtico calvario, pero de algún modo el argumento de mi madre era tan contundente que no lo podía contradecir. Y, además, fundamental : no disponía yo de dinero ni para la prenda lista ni para el corte de tela en la telería. Así que íbamos al negocio de tela, en el negocio de tela casi nunca estaba exactamente la misma tela pero sí una muy parecida, una casi igual, que mi madre convertía en un "idéntico" que ya llevaba en sí el germen del engaño. A partir de ahí todo empezaba a estar levemente corrido, levemente parecido a sí mismo y en esa seguidilla, ese agolpamiento de "casis", la prenda original terminaba convirtiéndose en otra, con todas las intenciones de la prenda industrial pero sin ser esa prenda industrial.

Lo último que recuerdo de Dolores y su familia tensa es que uno de los últimos días de veraneo, con la desilusión del cumpleaños encima, Clarita está en penitencia y no le permiten meterse al mar porque -y esta es información que filtra Sebastián- le habría chupado el culo a una Barbie. Habiendo sido descubierta en esa acción deleznable, la niña era castigada con abstinencia de mar.

6 De los Baéz nos despedimos a los abrazos y con intercambio de direcciones. Lo último que me une a mi amiga es que en mi cumpleaños de otoño, cuando rubrico las tarjetitas de invitación, una lleva el nombre de Dolores Báez. Pero esa tarjeta nunca abandona mi domicilio y se convierte así en el epitafio de lo que erróneamente había comenzado como un romance. 